\title{
Investigation of Allium sativum's Protective Effect on Ovarian Reserve in an Experimental Ovarian Injury Model
}

\author{
Investigación del Efecto Protector de Allium sativum de la Reserva \\ Ovárica en un Modelo Experimental de Lesión Ovárica
}

Gürhan Güney ${ }^{1}$; Cihan Kaya²; Serkan Yildırim³ ${ }^{3}$ Gökhan Oto ${ }^{4}$; Suat Ekin ${ }^{5}$ \& Hülya Özdemir ${ }^{4}$

GÜNEY, G.; KAYA, C.; YILDIRIM, S.; OTO, G.; EKIN, S. \& ÖZDEMIR, H. Investigation of Allium sativum's protective effect on ovarian reserve in an experimental ovarian injury model. Int. J. Morphol., 36(2):395-401, 2018.

SUMMARY: We aimed to evaluate the effects of detorsion and Allium sativum (garlic oil) treatment on the ovarian reserve in an ovarian torsion model. Ovarian torsion may lead to loss of ovarian tissue and infertility. It is an experimental rat study that was carried out on 16 sets of ovaries each, one for treatment group and a control group. In the control group, the procedure involved only the surgically opening and closing the abdomen. Bilateral adnexal torsion/detorsion was performed after a 3-hour ischemia period for the detorsion-only group. The detorsion + Allium sativum group received a $5 \mathrm{ml} / \mathrm{kg}$ dose of Allium sativum intraperitoneally, 2 hours before surgery. After the second surgery, removed ovarian samples were evaluated for follicle counts, damage scores and other parameters. Primordial, preantral, small antral and large antral follicle counts were significantly higher in the detorsion + Allium sativum group. Degeneration, congestion, hemorrhage ,inflammation and total damage scores were significantly elevated in the detorsion only group compared to those for the detorsion + Allium sativum group. Finally, there was a significant correlation between AMH alterations and postoperative, preantral follicle count ( $<<0.05)$. As a conclusion detorsion + Allium sativum treatment may be effective in protecting the ovarian reserve after torsion.

KEY WORDS: Anti-Müllerian hormone; Detorsion; Allium sativum; Ovarian reserve; Oxidative stress.

\section{INTRODUCTION}

Ovarian torsion is a gynaecologic emergency characterized by necrosis after ischemia; it is caused by partial or complete rotation of the ovary, twisting its supporting ligaments. As symptoms and signs cannot be fully detected, diagnosis is usually delayed, resulting in ischemia and necrosis. This can lead to loss of ovarian tissue and infertility (Bekci et al., 2016). The traditional treatment method is surgical removal of the ovarian tissue in the shortest possible time, without detorsion, because it may cause a thromboembolism. However, recent studies have found that thromboembolisms and other complications rarely occur due to detorsion; thus, this threat does not justify refraining from such radical treatments (Campbell et al., 2015).

Conservative de-torsion and follow-up methods enable clinicians to observe and anticipate the negative effects of ischemia at the time of torsion as well as reperfusion damage on the ovarian reserve. Therefore, to protect ovarian tissue against ischemia and reperfusion injury, new treatment modalities have been the subject of recent research (Sahin Ersoy et al., 2016). One of the most popular mechanisms for investigating reperfusion injury is inducing reaction of a large amount of free oxygen radicals with cellular proteins, nucleic acids, and lipids to inflict damage on cellular structures (Liu et al., 2016).

Garlic oil (Allium sativum) has been used in cooking throughout human history. Although its antioxidant and antiinflammatory effects have been shown in various tissues, no study has investigated its effects on ovarian tissue (Schwingshackl et al., 2016). Thus, we propose that, in addition to classical therapies, Allium sativum may be a viable option to protect ovarian tissue against ischemia and reperfusion damage due to its antioxidant, anti-inflammatory, and fibrinolytic properties.

\footnotetext{
${ }^{1}$ Department of Obstetrics and Gynecology, Sakarya University Education and Research Hospital, Sakarya, Turkey.

${ }^{2}$ Department of Obstetrics and Gynecology, Bakırköy Dr. Sadi Konuk Education and Research Hospital, Istanbul, Turkey.

${ }^{3}$ Department of Pathology, Atatürk University, Faculty of Veterinary Medicine, Erzurum, Turkey.

${ }^{4}$ Department of Pharmacology, Yuzuncu Yil University, Faculty of Medicine, Van, Turkey.

${ }^{5}$ Department of Biochemistry, Yuzuncu Yil University, Faculty of Science, Van, Turkey.
} 


\section{MATERIAL AND METHOD}

This study was conducted at the experimental laboratory of Van University, Faculty of Medicine in Turkey. Ethical approval was obtained from the Center's Ethics Committee for Experimental Animals for Use in Scientific Studies (Project number: 27552122-385).

Animal maintenance and treatment. Animals had free access to food and water, and were put on a 14-hour light cycle. The animals weighing 180-260 g were housed and cared for in accordance with the Canadian Council on Animal Care (Olfert et al., 1993). A power analysis indicating the minimum sample size required for the study (a error $=0.05$ and $1-b=0.8$ ) revealed that $>12$ sets of ovaries were required for each study group. Thus, we included 16 sets of ovaries per group because $20 \%$ of the animals were typically lost during procedures.

After acclimation, performing daily vaginal smears allowed us to ascertain the stage of the rats estrous cycles. Rats with at least three consecutive 4-day estrous cycles were prepared for surgery. To do so, the animals were anesthetized by applying $50 \mathrm{mg} / \mathrm{kg} 10 \%$ ketamine hydrochloride (Ketasol@; Richter Pharma AG, Wels, Austria) and 5 mg/kg $2 \%$ xylazine (Rompun®; Bayer HealthCare LLC, PA, USA) intramuscularly. After anesthesia, one rat died in each group.

To measure AMH levels, a 1-mL preoperative blood sample was drawn from the right jugular vein of each rat. Before the operation, the abdominal skin was shaved and disinfected with $10 \%$ povidone-iodine solution (Batticon $₫$; Adeka Laboratories, Samsun, Turkey). In the control group, the procedure comprised only the surgical opening and closing of the abdomen. The ovaries and uterine horns were exposed in the experimental groups by performing a 3-cm midline incision. Bilateral adnexal torsion (3-hour ischemia) was performed for the detorsion-only group (3-hour ischemia). Including the tubo-ovarian vessels, the adnexa were rotated $360^{\circ}$ clockwise, then fixed to the abdominal sidewall (Fig. 1).

Detorsion (reperfusion) was performed after a 3-hour torsion period. The detorsion + Allium sativum group received $5 \mathrm{ml} / \mathrm{kg}$ Allium sativum (Oleum Allii Sativi®, Arifoglu Baharat, Istanbul, Turkey) subcutaneously 2 hours before surgery. Abdominal incisions were closed using two layers of 4-0 polyglycolic acid suture (Vicryl®; Ethicon, Inc., Johnson \& Johnson, Amersfoort, the Netherlands) to repair the peritoneum and a 3-0 polyglactin suture for the skin. Animals were then housed separately using a controlled temperature of $22 \pm 2{ }^{\circ} \mathrm{C}$ and a 14-hour light cycle. All rats

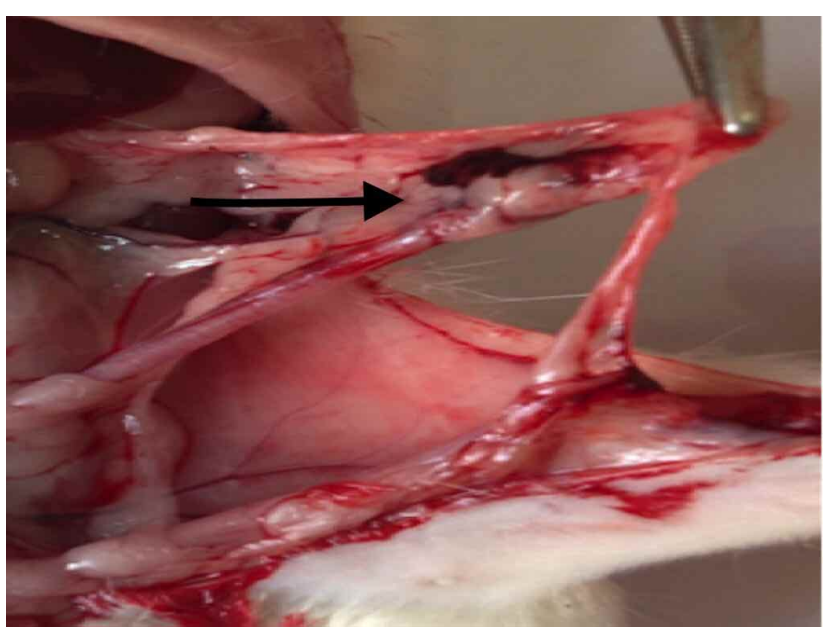

Fig. 1. Detorsion-only group. The ovarium appears to be dark brown and sticks well to the peritoneum.

had free access to food and water after recovering from surgery. To prevent tissue from drying at room temperature, the surgery time was limited to 15 minutes for each rat. All surgical procedures were performed by the same researchers.

Tissue sample collection and histopathology. A 1-mL serum sample was taken from the right jugular vein of each rat to measure post-operative serum AMH levels following the 14-day recovery period. In addition, ovaries were removed at the end of the second surgery. Rats were killed via cervical dislocation, and a single pathologist, who was blind to the origin of the samples, evaluated the ovarian tissue samples.

Tissues excised for pathological analyses were fixed in $10 \%$ buffered formalin solution for 24 hours. Following fixation, a routine tissue-processing procedure was performed, and the samples were embedded in wax blocks. Using microtome, paraffin wax blocks were divided into 4mm-thick pieces and stained with hematoxylin and eosin (H-E). A histological method used for follicle count was adopted from Alexandra et al. (Apud Ozler et al., 2013).

At least five microscopic areas were examined for each specimen using a Nikon Eclipse 80i light microscope (Nikon, Tokyo, Japan). The follicles were then divided into the following four groups according to the mean diameter: primordial $(<20 \mu \mathrm{m})$, preantral $(20-220 \mu \mathrm{m})$, small antral (221-310 $\mu \mathrm{m})$, and large antral (311-370 $\mu \mathrm{m})$. Atretic follicles were defined according to the description in Osman et al. (1985). The extents of follicular cell degeneration (granulosa cells), vascular congestion, hemorrhage, and presence of inflammatory cells were used as criteria to estimate ovarian damage scores using a $0-3$ scale $(0=$ none; $1=$ mild; $2=$ moderate; and $3=$ severe ). 
Measurements of serum levels of AMH. Collected whole blood samples were rapidly centrifuged at $4,000 \mathrm{rpm}$ for 10 minutes, and serum was transferred to Eppendorf tubes. The samples were then transferred to ice and kept at $-80^{\circ} \mathrm{C}$ until needed for analysis. An automatic enzyme-linked immunosorbent assay (ELISA) system from a commercially available kit (Omentin ELISA kit ${ }^{\oplus}$, Eastbiopharm Co. Ltd., Hangzhou, PRC) was used to determine serum AMH levels, using a quantitative, biotin-based double-antibody sandwich technique.

Briefly, microplates were precoated with a Mullerianinhibiting substance (MIS/AMH)-specific antibody. Standards and samples were pipetted into the wells, and any MIS/AMH present was bound by the immobilized antibody. The wells were then incubated with an enzyme-conjugated antibody specific to MIS/AMH. After washing to eliminate unbound antibody enzyme complexes, substrate solutions A and B were added to the wells and the solution turned blue, followed by a change to yellow upon addition of acid. The color development was stopped and the intensity of the color was measured using a microplate reader with a 450-nm absorption wavelength.

Measurements of serum levels of xanthine oxidase. An ELISA kit was used with the same biotin double antibody sandwich technique to assay murine xanthine oxidase (XOD). XOD was added to the well plate that had been pre-coated with a XOD monoclonal antibody. The wells were then incubated, and anti-XOD antibodies labeled with biotin were subsequently added to unite with streptavidin-HRP to form an immune complex. Unbound enzymes were removed after incubation and washing. Substrates A and B were then added, turning the solution blue, then yellow, upon addition of acid. Both the chromatic shades of the solution and the concentration of murine XOD were positively correlated (According to Eastpharm, XOD instruction manual, Cat No CK-E90236).

Measurements of total serum oxidant (TOC) and total antioxidant capacity (TAC). Total oxidant capacity (TOC): TOC was determined using a novel automated measurement method developed by Erel (2005) (TOC assay kit ${ }^{\circledR}$, Rel Assay Diagnostic, Gaziantep, Turkey). Oxidants present in a given sample oxidize the ferrous O-dianisidine complex to a ferric ion. The oxidation reaction is enhanced by glycerol molecules, which are abundantly present in the reaction medium. The ferric ion forms a colored complex with xylenol orange in an acidic medium. The chromatic intensity, which can be measured using a spectrophotometer, is related to the total amount of oxidant molecules present in the sample.

Briefly, $75 \mu \mathrm{l}$ of serum and $500 \mu \mathrm{l}$ of reagent $1\left(\mathrm{H}_{2}\right.$ $\left.\mathrm{SO}_{4} 25 \mathrm{mM}, \mathrm{pH} 1.75\right)$ were added to the test tube and stirred. Twenty-five $\mu \mathrm{l}$ of reagent $2\left(\mathrm{H}_{2} \mathrm{SO}_{4} 25 \mathrm{mM}, \mathrm{pH} 1.75,5 \mathrm{mM}\right.$ of ferrous ion, and $10 \mathrm{mM}$ of O-dianisidine were then added to the mixture. The absorption of the solution at $660 \mathrm{~nm}$ was measured at $30 \mathrm{~s}$ (value A1) and 5 min (value A2) after mixing. The assay was calibrated with hydrogen peroxide and the results were expressed in terms of $\mu \mathrm{mol} \mathrm{H}_{2} \mathrm{O}_{2}$ equivalent/l for the serum samples (Erel).

Total antioxidant capacity (TAC): TAC values were determined using a novel automated colorimetric measurement method developed by Erel (TAC assay kit ${ }^{\circledast}$, Rel Assay Diagnostic, Gaziantep, Turkey). In this method, a hydroxyl radical, the most potent biological radical, is produced via a Fenton reaction and then reacted with the colorless Odianisidine substrate to produce the dianisyl radical, which has a bright, yellowish-brown in color. Upon adding a given amount of sample, the oxidative reactions initiated by the hydroxyl radicals present in the reaction mix are suppressed by the antioxidant components within the sample, thereby preventing the color change. This provides an effective measurement of the total antioxidant capacity of the sample.

Briefly, $30 \mu \mathrm{l}$ of serum and $500 \mu \mathrm{l}$ of reagent 1 (acetate buffer $0.4 \mathrm{~mol} / \mathrm{l}, \mathrm{pH} 5.8$ ) were added to the test tube and stirred. Seventy-five $\mu 1$ of reagent 2 (acetate buffer $0.4 \mathrm{~mol} /$ 1 , and ABTS $30 \mathrm{mmol} / \mathrm{l}$ ) were then added to the mixture. The absorption of the solution at $660 \mathrm{~nm}$ was measured at $30 \mathrm{~s}$ (value A1) and $5 \mathrm{~min}$ (value A2) after mixing. The results were expressed as mmol Trolox equivalents/l (Eq/l) for serum samples (Erel).

Statistical analysis. Descriptive statistical methods (mean, standard deviation, min-max measurements) were used for data analyses, which were performed using IBM SPSS Statistics for Windows (Version 20.0. Armonk, NY: IBM Corp.). A p-value of $<0.05$ was considered statistically significant. A single-sample Kolmogorov-Smirnov test was performed to evaluate the distribution of the data. In addition, a Kruskal-Wallis test was used to compare differences in scores between the groups, while the Bonferroni corrected Mann-Whitney U test was used to compare differences between subgroups. A Spearman correlation analysis was performed to evaluate relations between histopathological results and blood sample alterations.

\section{RESULTS}

Upon examining rat tissues of all groups for histopathology, we revealed primordial, preantral, small antral, large antral, and corpus luteum follicles, and did not observe any pathologies in the control group (Fig. 2). While severe hyperemia, hemorrhage, degeneration, and necrosis 
were observed in granulosa cells of detorsioned ovaries, severe hemosiderin pigment deposition was also seen in interfollicular regions (Figs. 3, 4).

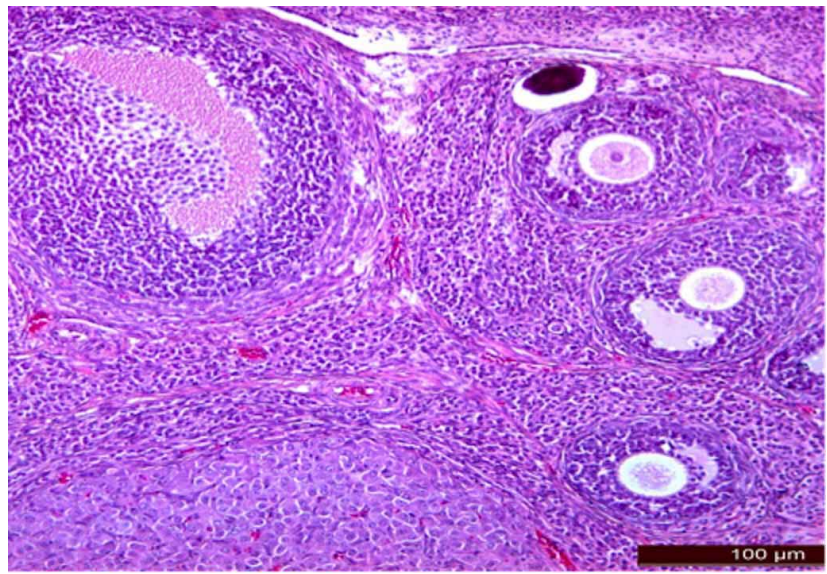

Fig.. 2. Normal histology of the rat ovaries (H-E $100 \mu \mathrm{m})$.

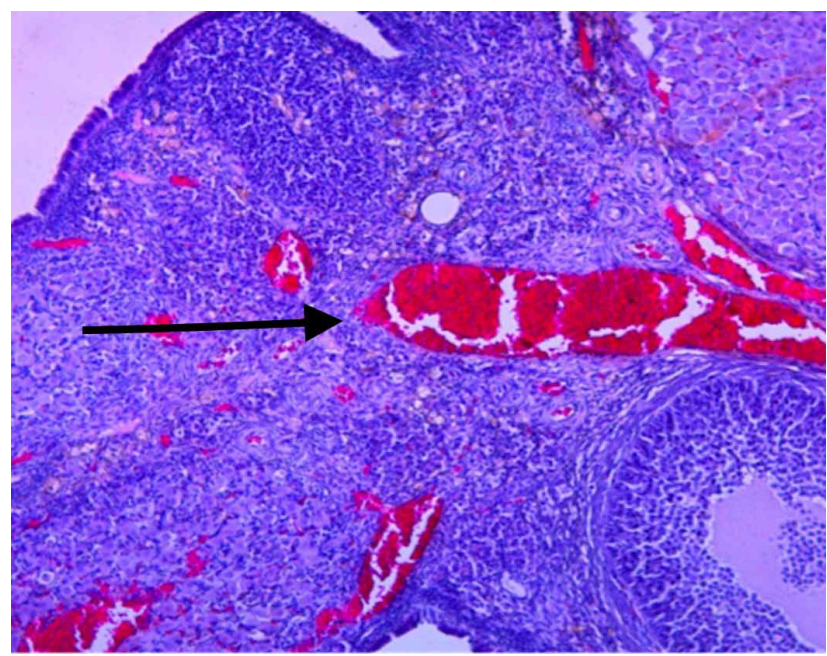

Fig. 3. The black arrow shows severe hyperemia and hemorrhage (H-E $100 \mu \mathrm{m})$.

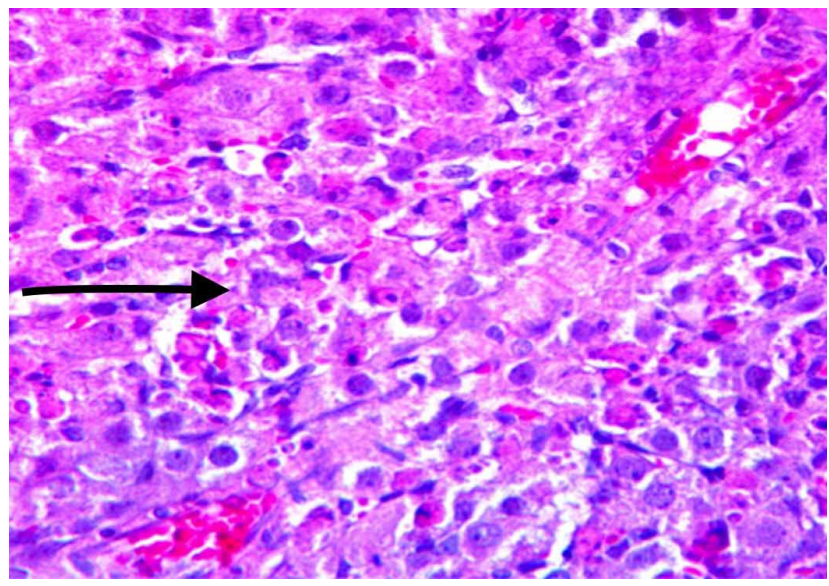

Fig. 4. The black arrow shows cell degeneration and necrosis (H-E $20 \mu \mathrm{m})$.
There were statistically significant differences between study groups in primordial, preantral, small antral, large antral, and corpus luteum counts. Further subgroup analyses were performed to elucidate differences between study groups in greater depth. Primordial $(p<0.001)$, preantral $(p<0.001)$, small antral ( $\mathrm{p}<0.001)$, and large antral (p:0.002) follicle counts were significantly higher in the detorsion + garlic oil group than those for the detorsion-only group (Table I).

There were also statistically significant differences between study groups in damage scores such as degeneration, congestion, hemorrhage, inflammation, and total damage scores. In subgroup analysis, degeneration $(\mathrm{p}<0.001)$, congestion ( $\mathrm{p}<0.001)$, hemorrhage ( $\mathrm{p}: 0.001)$, inflammation $(\mathrm{p}<0.001)$, and total damage $(\mathrm{p}<0.001)$ scores were significantly elevated in the detorsion-only group compared to those for the detorsion + Allium sativum group.

There were statistically significant differences between study groups in post-TAS, TAS alteration, post-OSI, pre-XOD, post XOD, and XOD alterations. In subgroup analysis, post$\mathrm{XOD}(\mathrm{p}<0.001)$ and XOD alterations $(\mathrm{p}<0.001)$ were increased in the detorsion + Allium sativum group compared to those for the detorsion only group. However, there was no statistically significant difference between study groups in preAMH, post-AMH, AMH alteration, pre-TOS, post-TOS, and TOS alteration (Tables II, III).

There was a significant correlation between AMH alterations and postoperative, preantral follicle count $(p<0.05)$. In addition, there were statistically significant correlations between primordial, preantral, small antral, large antral, and corpus luteum counts, as well as degeneration, congestion, hemorrhage, inflammation, total damage scores, and TAS alteration levels. However, there were no significant correlations between OSI, XOD alterations, and histopathological results (Table IV).

\section{DISCUSSION}

To date, the conventional treatment of ovarian torsion has not been replaced by ovary-conserving surgery because of serious complications such as thromboembolism, malignancy, and even peritonitis. However, as it is understood that many of these complications are not overly frequent, ovary-preserving treatment may be accepted as a safe and effective alternative treatment method (Oskaylı et al., 2015).

In the clinical follow-up period after detorsion, especially in cases where the black and bluish color of adnexal tissue did not change, live ovarian tissue was 
Table I. Comparison of histopathological results of the study groups.

\begin{tabular}{lllll}
\hline & $\begin{array}{l}\text { Control } \\
\text { mean } \pm \text { SD(Range) }\end{array}$ & $\begin{array}{l}\text { Detorsion } \\
\text { mean } \pm \text { SD(Range) }\end{array}$ & $\begin{array}{l}\text { Detorsion+garlic oil } \\
\text { mean } \pm \text { SD(Range) }\end{array}$ & $P$ value \\
\hline $\begin{array}{l}\text { Follicle count } \\
\text { Primordial }\end{array}$ & $9.88 \pm 0.64(9-11)$ & $4.76 \pm 0.7(4-6)$ & $8.76 \pm 0.7(8-10)$ & $<0.001$ \\
Preantral & $7.26 \pm 1.59(4-9)$ & $3.13 \pm 0.64(2-4)$ & $6.26 \pm 0.89(5-7)$ & $<0.001$ \\
Small antral & $5 \pm 0.53(4-6)$ & $3.26 \pm 0.7(2-4)$ & $5.13 \pm 0.64(4-6)$ & $<0.001$ \\
Large antral & $4.25 \pm 0.89(3-6)$ & $2 \pm 0.53(1-3)$ & $3 \pm 0.53(2-4)$ & $<0.001$ \\
Corpus luteum & $8 \pm 0.76(7-9)$ & $10 \pm 0.53(9-11)$ & $8.76 \pm 0.7(8-10)$ & 0.001 \\
Atretic & $1 \pm 0.53(0-2)$ & $1.38 \pm 0.51(1-2)$ & $1.6 \pm 0.53(1-2)$ & 0.187 \\
Damage score & & & & $<0.001$ \\
Degeneration & $0.13 \pm 0.35(0-1)$ & $2.88 \pm 0.36(2-3)$ & $0.88 \pm 0.36(0-1)$ & $<0.001$ \\
Congestion & $0(0)$ & $2.76 \pm 0.47(2-3)$ & $0.88 \pm 0.36(0-1)$ & $<0.001$ \\
Hemorrhage & $1 \pm 0.53(0-2)$ & $2.76 \pm 0.47(2-3)$ & $1.76 \pm 0.47(1-2)$ & $<0.001$ \\
Inflammation & $1 \pm 0.53(0-2)$ & $2.88 \pm 0.36(2-3)$ & $0.88 \pm 0.36(0-1)$ & $<0.001$ \\
Total damage & $2.13 \pm 0.83(1-4)$ & $11.12 \pm 0.83(10-12)$ & $4.6 \pm 0.76(3-5)$ & \\
\hline
\end{tabular}

Table II. Comparison of blood samples of the study groups.

\begin{tabular}{lcccc}
\hline & $\begin{array}{c}\text { Control } \\
\text { mean } \pm \text { SD(Range })\end{array}$ & $\begin{array}{c}\text { Detorsion } \\
\text { mean } \pm \text { SD(Range) }\end{array}$ & $\begin{array}{c}\text { Garlic+Detorsion } \\
\text { mean } \pm \text { SD(Range) }\end{array}$ & $P$ value \\
\hline Pre AMH & $0.73 \pm 0.36(0.2-1.1)$ & $0.69 \pm 0.14(0.56-0.88)$ & $0.84 \pm 0.19(0.48-1)$ & 0.456 \\
Post AMH & $0.75 \pm 0.32(0.1-1)$ & $0.55 \pm 0.31(0.08-1.03)$ & $0.81 \pm 0.11(0.6-0.9)$ & 0.084 \\
AMH alteration & $-0.02 \pm(-0.5-0.43)$ & $0.14 \pm 0.36(-0.47-0.74)$ & $0.02 \pm 0.13(-0.2-0.15)$ & 0.423 \\
Pre TAS & $1.13 \pm 0.36(1-2)$ & $1.260 .47(1-2)$ & $1.13 \pm 0.36(1-2)$ & 0.75 \\
Post TAS & $1.88 \pm 0.36(1-2)$ & $1(1)$ & $1.13 \pm 0.36(1-2)$ & $<0.001$ \\
TAS alteration & $-0.75 \pm 0.46(-1-0)$ & $0.26 \pm 0.46(0-1)$ & $0 \pm 0.53(-1-1)$ & 0.004 \\
Pre TOS & $20.26 \pm 3.61(14-26)$ & $20 \pm 4.11(13-26)$ & $20 \pm 2.45(17-24)$ & 0.864 \\
Post TOS & $19.26 \pm 3.2(15-24)$ & $23.13 \pm 3.57(16-27)$ & $21.13 \pm 1.96(17-24)$ & 0.059 \\
TOS alteration & $1 \pm 4.8(-5-8)$ & $-3.12 \pm 5.56(-11-8)$ & $-1.1 \pm 2.8(-5-4)$ & 0.257 \\
Pre OSI & $1.38 \pm 0.51(1-2)$ & $1.76 \pm 0.70(1-3)$ & $1.38 \pm 0.52(1-2)$ & 0.415 \\
Post OSI & $1.13 \pm 0.36(1-2)$ & $2 \pm 0.53(1-3)$ & $1.38 \pm 0.52(1-2)$ & 0.009 \\
OSI alteration & $0.26 \pm 0.46(0-1)$ & $-0.26 \pm 1.16(-2-2)$ & $0 \pm 0.92(-1-1)$ & 0.431 \\
Pre XO & $12.89 \pm 1.42(1-2)$ & $8.46 \pm 3.14(5-13)$ & $6.23 \pm 2.22(3-9)$ & 0.002 \\
Post XO & $10.04 \pm 1.14(9-12)$ & $9.71 \pm 1.36(8-11)$ & $12.6 \pm 1.64(10-15)$ & 0.004 \\
XO alteration & $2.86 \pm 1.8(0-5.8)$ & $-1.26 \pm 2.13(-3.9-2.7)$ & $-6.3 \pm 3(-12.1--2.7)$ & $<0.001$ \\
\hline
\end{tabular}

observed. Despite the necrotic appearance of ovaries, almost no publications have reported an increase in the risk of thromboembolism, regardless of whether or not the ovaries were left detorsioned. Contrary to common belief, the rarity of this complication often leads clinicians to be optimistic; however, long-term follow-ups unexpectedly revealed reperfusion damage (Calis et al. 2015).

In many studies, the most important pathophysiological mechanism explaining reperfusion damage is increased blood flow after reperfusion, which produces much more oxygen free radicals such as lactic acid, cyanide oxidase via neutrophils, and apoptosis after cellular membrane peroxidation. These events are followed by a loss of function in various tissues (Kaya et al. 2014).
There are also many studies on ovarian ischemia reperfusion (I/R) injury and its prevention strategies. One such study by Parlakgumus et al., revealed that atorvastatin, a well-known statin, protects ovarian tissue by reducing neutrophil infiltration and activating the superoxide dismutase enzymes. In other words, this statin increases antioxidant and anti-inflammatory responses. Another study by Gencer et al., demonstrated that quercetin is a powerful antioxidant and anti-inflammatory agent that helps to prevent I/R damage. Based on these studies, antiinflammatory-antioxidant agents may protect ovaries from I/R injury (Yigiter et al, 2011). Furthermore, a rat study by Oral et al. (2011) showed that Montelukast's antiinflammatory and antioxidant effects decreased the incidence of I/R injury. 
Table III. Bonferroni corrected Mann Whitney U test of the study groups.

\begin{tabular}{lccc}
\hline & $\begin{array}{c}\text { Control/ } \\
\text { Detorsion/ }\end{array}$ & $\begin{array}{c}\text { Control/ Garlic+ } \\
\text { Detorsion/p }\end{array}$ & $\begin{array}{c}\text { Detorsion/ } \\
\text { Garlic }+\end{array}$ \\
\hline Primordial & $<0.001$ & 0.003 & $<0.001$ \\
Preantral & $<0.001$ & 0.03 & $<0.001$ \\
S mall antral & $<0.001$ & 0.24 & $<0.001$ \\
Large antral & $<0.001$ & 0.001 & 0.002 \\
Corpus luteum & $<0.001$ & 0.03 & 0.001 \\
Degeneration & $<0.001$ & 0.003 & $<0.001$ \\
Congestion & $<0.001$ & $<0.001$ & $<0.001$ \\
Hemorrhage & $<0.001$ & 0.009 & 0.001 \\
Inflammation & $<0.001$ & 0.24 & $<0.001$ \\
Total damage & $<0.001$ & $<0.001$ & $<0.001$ \\
Post TAS & $<0.001$ & 0.003 & 0.24 \\
TAS alteration & 0.001 & 0.009 & 0.168 \\
Post OSI & 0.002 & 0.147 & 0.021 \\
Pre XO & 0.009 & $<0.001$ & 0.06 \\
Post XO & 0.127 & 0.001 & $<0.001$ \\
XO alteration & 0.001 & $<0.001$ & $<0.001$ \\
\hline
\end{tabular}

In several recent studies, Allium sativum has been shown to be a powerful antioxidant. Animal experiments have discovered anti-inflammatory, vasodilatory, hypotensive, cholesterol-lowering, antimicrobial, antiallergic, and immunomodulatory effects (Nasr, 2014). Its antioxidant effects involve clearing reactive oxygen species from cells. It also inhibits lipid peroxidation and reduces $\mathrm{I} / \mathrm{R}$ injury by inhibiting the oxidative modification of low-density lipoprotein. In addition, Allium sativum prevents DNA damage by lowering the levels of oxidative stress markers (Hassan et al., 2010). Anim-Nyame et al. (2004) shows that Allium sativum (garlic oil) also reduces precapillary vessel resistance of the microvascular bed by increasing IL-6 secretion from the vascular endothelium during a hypoxic state. Thus, this event resulted in increased tissue perfusion (Anim-Nyame et al.). Based on this result, we suggest that Allium sativum may even indirectly increase tissue perfusion in perfusion disturbances.
In our study, we injected a single $5 \mathrm{mg} / \mathrm{kg}$ dose of Allium sativum subcutaneously, 2 hours before a detorsion period. We used the same dose as that in a rat adhesion model (Sahbaz et al., 2014). Previous studies show that 3 hours of continuous ischemia during torsion is necessary to produce some histological changes in ovaries. In doing so, we used a 3-hour period between torsion and detorsion (Oral et al.).

$\mathrm{AMH}$ is a dimeric glycoprotein and a member of the transforming growth factor beta family. This hormone is secreted from preantral and small antral follicles, and quickly detects changes in microvascular perfusion; therefore, it provides us with an ability to better assess the ovarian reserve. AMH levels can be viewed on any day of the menstrual cycle because their relative levels are not affected by the menstrual cycle (Atasever et al., 2016). In order to understand whether or not the ovarian reserve was affected by ischemia and reperfusion damage, we assessed preoperative and postoperative serum AMH levels and follicle count (Kaya et al., 2015).

Although we did not find a significant difference between preoperative and postoperative AMH levels, we observed a number of pre-antral follicles with AMH changes in the correlation analysis.

To assess oxidative stress levels, we investigated the preoperative and postoperative XOD and total antioxidant status-total oxidant status (TAS-TOS) activity levels. We found statistically significant differences between study groups for post-TAS, TAS, post-OSI, preXOD, post-XOD, and XOD alterations. However, there were no statistically significant differences in pre-TOS, post-TOS, and TOS alterations between study groups.

Table IV. Correlation analysis of the blood samples alterations and histopatological analysis of the study groups

\begin{tabular}{lccccc}
\hline & AMH alteration/r & TAS alteration $/ \mathrm{r}$ & TOS alteration $/ \mathrm{r}$ & OSI alteration $/ \mathrm{r}$ & XO alteration/r \\
\hline Primordial & -0.22 & $-0.49^{*}$ & 0.36 & 0.15 & 0.36 \\
Preantral & $-0.43^{*}$ & $-0.63^{* *}$ & 0.19 & 0.36 & 0.1 \\
Small antral & -0.25 & $-0.56^{* *}$ & 0.09 & 0.36 & -0.08 \\
Large antral & -0.35 & $-0.73^{* *}$ & 0.17 & -0.25 & 0.38 \\
Corpus luteum & -0.21 & $0.5^{*}$ & -0.31 & -0.36 & -0.14 \\
Atretic & -0.29 & 0.15 & $-0.59^{* *}$ & -0.21 & -0.34 \\
Degeneration & 0.38 & $0.58^{* *}$ & -0.24 & -0.26 & -0.26 \\
Congestion & 0.15 & $0.57^{* *}$ & -0.39 & -0.15 & -0.32 \\
Hemorrhage & 0.84 & $0.53^{* *}$ & -0.4 & -0.33 & -0.24 \\
Inflammation & 0.32 & $0.49^{*}$ & -0.29 & -0.25 & 0.1 \\
Total damage & 0.24 & $0.62^{* *}$ & -0.39 & & -0.3 \\
\hline
\end{tabular}

r: Correlation coefficient $* \mathrm{p}<0.05 \quad * * \mathrm{p}<0.01$ 
By comparing the number of primordial, pre-antral, small antral, large antral follicles, corpus luteum degeneration, congestion, hemorrhaging, and inflammation scores, we observed significant differences in terms of total damage score and TAS levels.

To the best of our knowledge, our study is the first to investigate Allium sativum effects on the ovarian reserve in a rat torsion/detorsion model. Primordial, pre-antral, small antral, large antral, and corpus luteum follicles in the detorsion + Allium sativum group were found to be significantly greater in number than those of the torsiononly group. Reducing the number of primordial and small antral follicles in the detorsioned group is also important for the ovarian reserve. This indicates that the detorsion is not able to sufficiently protect the ovarian reserve.

GÜNEY, G.; KAYA, C.; YILDIRIM, S.; OTO, G.; EKIN, S. \& ÖZDEMIR, H. Investigación del efecto protector de Allium sativum de la reserva ovárica en un modelo experimental de lesión ovárica. Int. J. Morphol., 36(2):395-401, 2018.

RESUMEN: Intentamos evaluar los efectos de la detorsión y el tratamiento con Allium sativum (aceite de ajo) en la reserva ovárica en un modelo de torsión ovárica. La torsión ovárica puede ocasionar pérdida de tejido ovárico e infertilidad. Este es un estudio experimental en ratas que se llevó a cabo en 16 sets de ovarios para cada grupo: tratamiento y control. En el grupo control, el procedimiento involucró solamente la apertura y el cierre quirúrgicos del abdomen. La torsión / detorsión anexial bilateral se realizó después de un período de isquemia de 3 horas para el grupo de solo detorsión. El grupo de detorsión + Allium sativum recibió una dosis de $5 \mathrm{ml} / \mathrm{kg}$ de Allium sativum por vía intraperitoneal, 2 horas antes de la cirugía. Después de la segunda cirugía, las muestras ováricas eliminadas se evaluaron para recuentos de folículos, puntajes de daño y otros parámetros. Los recuentos de folículos antrales primordiales, preantrales, antrales pequeños y grandes fueron significativamente mayores en el grupo con detorsión + Allium sativum. Los puntajes de degeneración, congestión, hemorragia, inflamación y daño total fueron significativamente elevados en el grupo de solo detorsión, en comparación con los del grupo de detorsión + Allium sativum. Finalmente, hubo una correlación significativa entre las alteraciones de $\mathrm{AMH}$ y el recuento de folículos preantrales postoperatorios $(\mathrm{p}<0,05)$. Como conclusión, el tratamiento con detorsión + Allium sativum puede ser eficaz para proteger la reserva ovárica después de la torsión.

PALABRAS CLAVE: Hormona antimulleriana; Detorsión; Allium sativum; Reserva ovárica; Estrés oxidativo.

\section{REFERENCES}

Anim-Nyame, N.; Sooranna, S. R.; Johnson, M. R.; Gamble, J. \& Steer, P. J. Garlic supplementation increases peripheral blood flow: a role for interleukin-6? J. Nutr. Biochem., 15(1):30-6, 2004.

Atasever, M.; Soyman, Z.; Demirel, E.; Gencdal, S. \& Kelekci, S. Diminished ovarian reserve: is it a neglected cause in the assessment of recurrent miscarriage? A cohort study. Fertil. Steril., 105(5):1236-40, 2016.

Bekci, T.; Polat, A. V.; Aslan, K.; Tomak, L.; Ceyhan Bilgici, M. \& Danaci, M. Diagnostic performance of diffusion-weighted MRI in the diagnosis of ovarian torsion: comparison of torsed and nonaffected ovaries. Clin. Imaging, 40(5):1029-33, 2016.

Calis, P.; Bozdag, G.; Karakoc Sokmensuer, L. \& Kender, N. Does ischemiareperfusion injury affect ovarian reserve and follicle viability in a rat model with adnexal torsion? Eur. J. Obstet. Gynecol. Reprod. Biol., 185:126-30, 2015.

Campbell, B. T.; Austin, D. M.; Kahn, O.; McCann, M. C.; Lerer, T. J.; Lee, K.; Thaker, S.; Herbst, K. W. \& Rader, C. M. Current trends in the surgical treatment of pediatric ovarian torsion: we can do better. J. Pediatr. Surg., 50(8):1374-7, 2015.

Erel, O. A new automated colorimetric method for measuring total oxidant status. Clin. Biochem., 38(12):1103-11, 2005.

Hassan, H. A.; Hafez, H. S. \& Zeghebar, F. E. Garlic oil as a modulating agent for oxidative stress and neurotoxicity induced by sodium nitrite in male albino rats. Food Chem. Toxicol., 48(7):1980-5, 2010.

Kaya, C.; Turgut, H.; Cengiz, H.; Turan, A.; Ekin, M. \& Yasar, L. Effect of detorsion alone and in combination with enoxaparin therapy on ovarian reserve and serum antimüllerian hormone levels in a rat ovarian torsion model. Fertil. Steril., 102(3):878-84, 2014.

Kaya, C.; Turgut, H.; Cengiz, H.; Turan, A.; Ekin, M. \& Yasar, L. The effect of tubal sterilization with the Pomeroy technique and bipolar electrocauterization on the ovarian reserve and serum anti-Müllerian hormone levels in a rat model. Eur. J. Obstet. Gynecol. Reprod. Biol., 185:108-13, 2015.

Liu, L.; Sun, Q.; Wang, R.; Chen, Z.; Wu, J.; Xia, F. \& Fan, X. Q. Methane attenuates retinal ischemia/reperfusion injury via anti-oxidative and anti-apoptotic pathways. Brain Res., 1646:327-33, 2016.

Nasr, A. Y. Protective effect of aged garlic extract against the oxidative stress induced by cisplatin on blood cells parameters and hepatic antioxidant enzymes in rats. Toxicol. Rep., 1:682-91, 2014.

Olfert, E. D.; Cross, B. M. \& McWilliam, A. A. Guide to the Care and Use of Experimental Animals. Ottawa, Canadian Council on Animal Care (CCAC), 1993. Available from: https://www.ccac.ca/Documents/Standards/Guidelines/ Experimental_Animals_Vol1.pdf

Oral, A.; Odabasoglu, F.; Halici, Z.; Keles, O. N.; Unal, B.; Coskun, A. K.; Kilic, C.; Surer, I. \& Salman, A. B. Protective effects of montelukast on ischemiareperfusion injury in rat ovaries subjected to torsion and detorsion: biochemical and histopathologic evaluation. Fertil. Steril., 95(4):1360-6, 2011.

Oskayli, M. Ç.; Durakbasa, Ç. U.; Masrabacı, K.; Mutus, H. M.; Zemheri, I. E. \& Okur, H. Surgical approach to ovarian torsion in children. J. Pediatr. Adolesc. Gynecol., 28(5):343-7, 2015.

Osman, P. Rate and course of atresia during follicular development in the adult cyclic rat. J. Reprod. Fertil., 73(1):261-70, 1985.

Ozler, A.; Turgut, A.; Soydinç, H. E.; Sak, M. E.; Evsen, M. S.; Alabalik, U.; Basarali, M. K. \& Deveci, E. The biochemical and histologic effects of adnexal torsion and early surgical intervention to unwind detorsion on ovarian reserve: an experimental study. Reprod. Sci., 20(11):1349-55, 2013.

Sahbaz, A.; Isik, H.; Aynioglu, O.; Gungorduk, K. \& Gun, B. D. Effect of intraabdominal administration of Allium sativum (garlic) oil on postoperative peritoneal adhesion. Eur. J. Obstet. Gynecol. Reprod. Biol., 177:44-7, 2014.

Sahin Ersoy, G.; Eken, M.; Tal, R.; Oztekin, D.; Devranoglu, B.; Isik Kaygusuz, E. \& Cevik, O. N-acetylcysteine leads to greater ovarian protection than enoxaparin sodium in a rat ovarian torsion model. Reprod. Biomed. Online, 33(1):93-101, 2016.

Schwingshackl, L.; Missbach, B. \& Hoffmann, G. An umbrella review of garlic intake and risk of cardiovascular disease. Phytomedicine, 23(11):1127-33, 2016.

Yigiter, M.; Halici, Z.; Odabasoglu, F.; Keles, O. N.; Atalay, F.; Unal, B. \& Salman, A. B. Growth hormone reduces tissue damage in rat ovaries subjected to torsion and detorsion: biochemical and histopathologic evaluation. Eur. J. Obstet. Gynecol. Reprod. Biol., 157(1):94-100, 2011.

Corresponding author:

Gürhan Güney

Department of Obstetrics and Gynecology

Sakarya University Training and Research Hospital

Sakarya - TURKEY

Email: gurhanguney@yahoo.com

Received: 11-09-2017

Accepted: 02-01-2018 